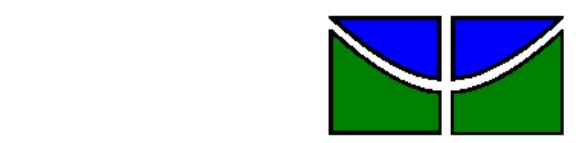

Universidade de Brasília

Faculdade de Economia, Administração e Contabilidade

Departamento de Administração

Curso de Graduação em Administração a distância

EUNICE APARECIDA DOS ANJOS

\title{
A GESTÃO DE DESEMPENHO POR COMPETÊNCIAS E O COMPROMETIMENTO NO TRABALHO
}

Brasília - DF 
EUNICE APARECIDA DOS ANJOS

\section{A GESTÃO DE DESEMPENHO POR COMPETÊNCIAS E O COMPROMETIMENTO NO TRABALHO}

Monografia apresentada a Universidade de Brasília (UnB) como requisito parcial para obtenção do grau de Bacharel em Administração.

Professor Orientador: MSc. Elizabeth Hirata

Brasília - DF 
Anjos, Eunice Aparecida dos.

A Gestão de Desempenho por Competências e o Comprometimento no Trabalho / Eunice Aparecida dos Anjos Brasília, 2010.

$44 \mathrm{f}$. : il.

Monografia (bacharelado) - Universidade de Brasília, Departamento de Administração - EaD, 2010.

Orientador: MSc. Elizabeth Hirata, Departamento de Administração.

1. Gestão de Desempenho por Competências. 2. Comprometimento no Trabalho. I. Título. 


\title{
EUNICE APARECIDA DOS ANJOS
}

\section{A GESTÃO DE DESEMPENHO POR COMPETÊNCIAS E O COMPROMETIMENTO NO TRABALHO}

\begin{abstract}
A Comissão Examinadora, abaixo identificada, aprova o Trabalho de Conclusão do Curso de Administração da Universidade de Brasília da aluna
\end{abstract}

\section{Eunice Aparecida dos Anjos}

\author{
MSc, Elizabeth Hirata \\ Professor-Orientador \\ Profa.MSc, Elizabeth Hirata \\ Professor-Examinador \\ Profa.Dra.Juliana Barreiros Porto \\ Professor-Examinador
}

Brasília, .04. de dezembro de 2010 
À Eline, Elenice, Eliene, Leandro, Helena e Maria Eduarda, meus eternos amores. 
AGRADECIMENTOS

Ao Banco do Brasil S/A, ao corpo docente da UAB $A D M$ EaD, meus sinceros agradecimentos pela oportunidade.

À minha filha Eliene, que sempre me auxilia na arte final. 
"E elogiou o senhor o administrador infiel porque se houvera atiladamente, porque os filhos do mundo são mais hábeis na sua própria geração dos que os filhos da luz." Lucas, 16:8 


\section{RESUMO}

Objetivou-se nesta pesquisa descrever a percepção dos funcionários de uma instituição pública bancária acerca da gestão de desempenho baseada nas competências e identificar o seu comprometimento com o trabalho. $O$ tema proposto teve origem na necessidade de aprofundar o conhecimento e de saber como aplicar as noções de competências, desempenho e comprometimento organizacional e também de compreender como essas noções estão articuladas entre si e com o mundo do trabalho. A pesquisa caracteriza-se quanto à abordagem como quantitativa e com relação aos objetivos como descritiva. Os questionários foram aplicados pessoalmente e por e-mail, obtendo-se o retorno de 30 respondentes. A análise dos resultados sobre a percepção dos empregados acerca da Gestão de Desempenho por Competências parece apontar para a concordância com o modelo, principalmente quando se foca o desenvolvimento profissional e planejamento da carreira. A discordância paira sobre o processo avaliativo de desempenho. Apesar de relativa concordância de que a GDPC contribua para o aumento no comprometimento com o trabalho, foi identificada uma prevalência do vínculo normativo, ou seja, de acordo com a conceitualização de Meyer e Allen, o funcionário permanece na Empresa porque se sente obrigado. Competência, desempenho e comprometimento são alvos constantes de pesquisas e o alcance do objetivo proposto deve-se em conjunto ao suporte de questões ramificadas dessa premissa, da pesquisa realizada com base noutras experiências com semelhante escopo e também por ter sido pautada na vasta literatura disponibilizada na Academia. Ainda que limitado espera-se possa este trabalho contribuir para o enriquecimento dos conceitos e que se constitua mesmo uma provocação para novos estudos sobre o tema.

Palavras-chave: Desempenho. Competência. Comprometimento. 


\section{SUMÁRIO}

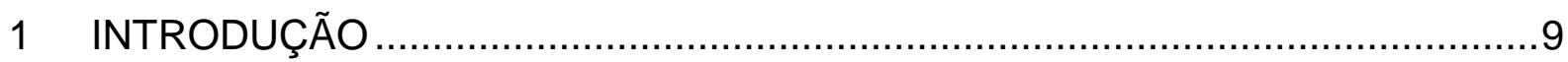

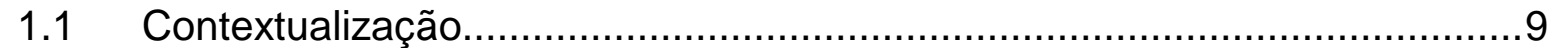

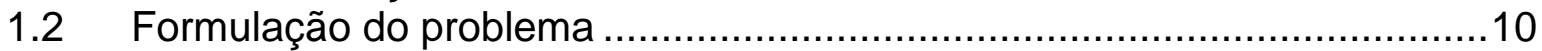

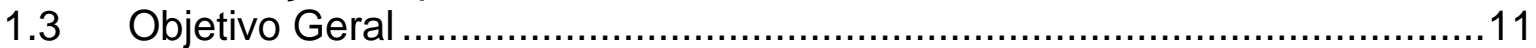

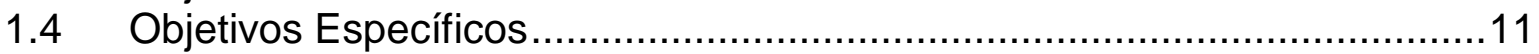

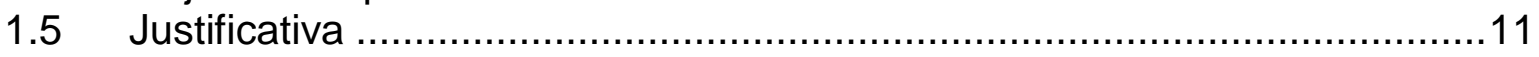

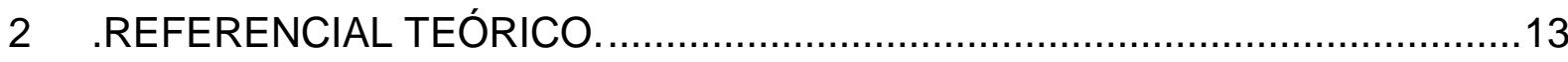

2.1 Evolução histórica da Gestão de pessoas no Brasil ................................13

2.2 Gestão de desempenho ...............................................................15

2.3 Gestão de competências ..............................................................18

2.4 Gestão de desempenho baseada nas competências ..............................20

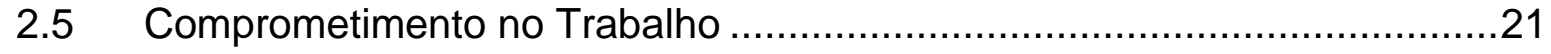

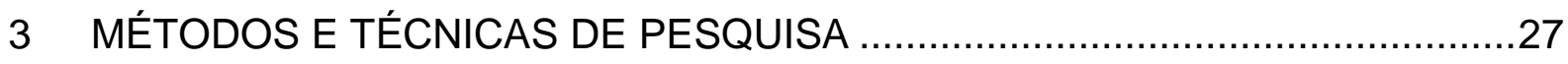

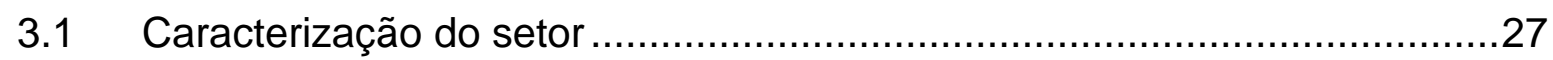

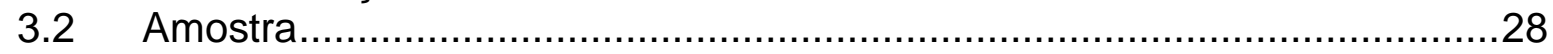

3.3 Caracterização dos instrumentos de pesquisa .......................................28

3.4 Procedimentos de coleta e de análise de dados......................................31

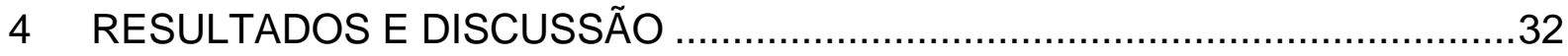

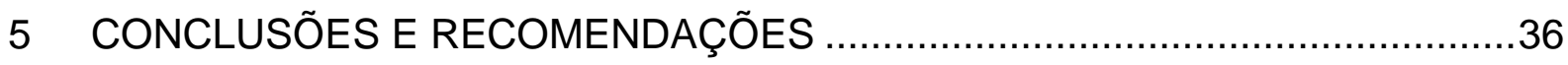

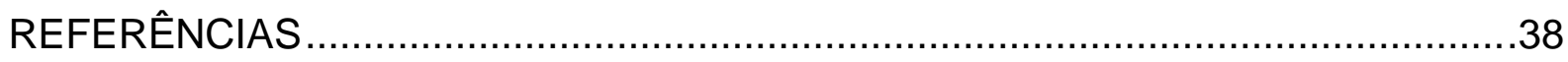

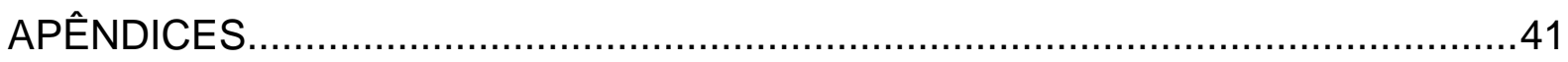

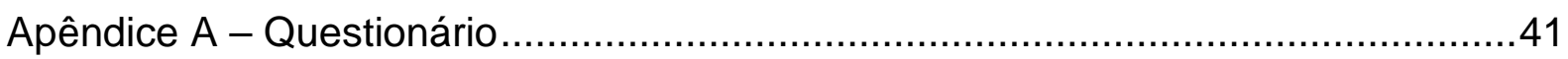




\section{INTRODUÇÃO}

A aplicação do conceito de competência na educação e no trabalho tem sido defendida conforme o relato de Guimarães (2000, p.130) pela "necessidade de se buscarem novas fórmulas que permitam estimular as capacidades de inovação, adaptação e aprendizagem, adequadas aos requisitos do desenvolvimento econômico contemporâneo".

Assim, pretende-se com esta pesquisa, aplicada numa instituição bancária pública que adotou o modelo de Gestão Pessoas denominado Gestão de Desempenho baseado nas Competências, descrever a percepção dos seus empregados acerca desse modelo e identificar o seu comprometimento com o trabalho.

Para tanto se faz uma revisão teórica sobre os principais conceitos de desempenho e competências, principiando-se por um breve histórico do processo evolutivo da Gestão de Pessoas nas organizações brasileiras.

Após, seguem-se subtópicos destinados a discussão de conceitos sobre gestão de desempenho, gestão de competências e de como surgiu a gestão de desempenho baseada nas competências, como resultado da junção desses dois modelos.

O último tópico do referencial teórico será dedicado à variável que triangula a pesquisa, qual seja o comprometimento no trabalho.

No capítulo 3, expõe-se a Metodologia em que se pautou a pesquisa, delineamento da amostra e população. Também se encontra descrito o instrumento utilizado na coleta de dados.

No capítulo 4, encontram-se os Resultados e Discussão e ao final, no capítulo 5, as Conclusões e Recomendações.

\subsection{Contextualização}

Os autores Brandão e Guimarães (2001) empreenderam estudos sobre desempenho, empregabilidade e competência, temas que eles consideram fragmentados e revestidos de diversas conotações no mundo pós-moderno, marcado por concepções variadas e contraditórias .Nesse contexto então é que 
surgiram várias teorias e pressupostos em gestão de pessoas como alternativas para a extinta área de Recursos Humanos, tais como gestão estratégica de recursos humanos (Taylor, Beechler e Napier, 1996); gestão de competências (Prahalad e Hamel, 1990; Heene e Sanchez, 1997); acumulação do saber (Arrègle,1995; Wright, Van e Bouty, 1995) e gestão do capital intelectual (Stewart, 1998).

Dentre essas alternativas encontra-se a Gestão de Desempenho baseada nas Competências, termo sugerido pelos autores Brandão e Guimarães (2001) em razão de considerar 0 caráter de complementaridade e interdependência entre competência e desempenho. Brandão e Guimarães (2001, p.14) concluíram em seus trabalhos a respeito das variáveis competência e desempenho que a utilização dessas ferramentas deve estar associada às "práticas de aprendizagem coletiva, desenvolvimento de equipes e gestão do conhecimento, entre outras, que ofereçam múltiplas oportunidades de crescimento profissional e estimulem as pessoas não apenas a desenvolver coletivamente competências mas também a compartilhá-las" para que, dessa forma, possam representar inovações nas práticas de gestão.

Na pesquisa de Bastos e Borges (2002), consta que subjacente aos novos modelos organizacionais está o pressuposto de que o comprometimento no trabalho se apresenta como requisito fundamental, uma vez que o envolvimento ou comprometimento do trabalhador parece crucial no sucesso dessas inovações. Os autores questionam quais são os impactos sobre o comprometimento individual com o trabalho nesse contexto de profundas alterações estruturais e culturais nas organizações? A busca de resposta para semelhante questionamento motivou a presente pesquisa cujo problema encontra-se formulado a seguir.

\subsection{Formulação do problema}

Como descrever a percepção dos funcionários de uma instituição bancária pública acerca da gestão de desempenho baseada nas competências e como identificar o nível do seu comprometimento com o trabalho nesse modelo de Gestão? 


\subsection{Objetivo Geral}

Descrever a percepção dos funcionários de uma instituição bancária pública acerca da gestão de desempenho baseada nas competências e identificar o nível do seu comprometimento no trabalho.

\subsection{Objetivos Específicos}

- Conhecer a percepção dos funcionários de uma instituição bancária pública a respeito da gestão de desempenho baseada nas competências.

- Identificar o nível de comprometimento no trabalho.

\subsection{Justificativa}

O tema proposto teve origem na necessidade de aprofundar o conhecimento e de saber como aplicar as noções de competências, desempenho e comprometimento no trabalho, bem como procurar compreender como essas noções estão articuladas entre si e com o mundo do trabalho. Acredita-se que somente a partir dessa compreensão é que será possível construir efetivamente novos modelos, pois caso contrário as inovações em práticas de Gestão de Pessoas continuarão a apresentar em sua essência os pressupostos tradicionais.

Dentre as inspirações para esta pesquisa, encontram-se os estudos realizados por Brandão e Guimarães (2001) sobre desempenho, empregabilidade e competência, temas considerados por eles fragmentados e revestidos de diversas conotações no mundo pós-moderno, marcado por concepções variadas e contraditórias.

A partir da extinção da área de Recursos Humanos, surgiram como alternativas várias teorias e pressupostos em gestão de pessoas dentre as quais encontra-se a sugestão dos autores que consiste na junção desses instrumentos, competência e desempenho, por acreditarem que se complementam, e também em razão da necessidade de um único modelo de gestão que integre as atividades de 
planejamento e avaliação de desempenho, com base nas competências essenciais à organização.

Estudos acadêmicos e a própria evolução histórica da administração apontam para a importância da Gestão de Pessoas na consecução dos objetivos empresariais. Ao longo desse percurso observa-se que a Gestão de Pessoas acompanha esse processo evolutivo com alterações nas terminologias e conceitos. Culmina nos nossos dias com o emprego da denominação Gestão de Pessoas e modelo de Gestão de Pessoas para denominar o sistema ou área de Recursos Humanos. Dentre os modelos de Gestão de Pessoas adotados ultimamente está o da Gestão de Desempenho baseado nas Competências, que enfatiza as pessoas como diferencial competitivo e determinante do sucesso organizacional.

Desenvolve-se no item a seguir o referencial teórico onde são apresentados os trabalhos da literatura relacionada por fornecerem elementos de contextualização e consistência à investigação formulada. 


\section{2 .REFERENCIAL TEÓRICO.}

Apresentam-se nos seguintes tópicos os trabalhos que contribuíram para a contextualização e fundamentos para o problema formulado. Inicia-se com uma breve revisão histórica a respeito da Gestão de Pessoas no Brasil, retratando a busca por uma gestão eficiente nas organizações brasileiras. Em seguida trata-se da Gestão de Desempenho que nesse processo evolutivo representa uma conquista recente e rapidamente ladeada pela Gestão de Competências. E em seguida será tratada a Gestão de Desempenho baseada nas Competências resultante da junção desses dois instrumentos. Ao final, será tratado o Comprometimento no trabalho, a segunda variável objeto do estudo..

\subsection{Evolução histórica da Gestão de pessoas no Brasil}

A estrutura histórica elaborada por Osso (2008) propicia uma visão qualitativa da evolução da Gestão de Pessoas desde a década de 30 até o presente século. Percebem-se mudanças não somente nas terminologias utilizadas, mas também no próprio perfil dos responsáveis pela gestão. O Quadro 1, a seguir, proporciona um panorama dessas transformações. O quadro 1 permite observar que o modelo de gestão de pessoas das organizações brasileiras apresentou uma evolução significativa conforme foi destacado por Demo (2008).

De acordo com a pesquisa de Brandão e Guimarães (2001) essa evolução decorre do processo de reestruturação produtiva e ressaltam ainda as grandes transformações sociais, econômicas, políticas e culturais enfrentadas pela sociedade contemporânea resultantes desse processo. Nas empresas essas transformações podem ser visualizadas nos processos de racionalização organizacional e técnicas que incorporam novas tecnologias e novos modelos de gestão ao ambiente empresarial. À medida em que cresce a concorrência no mercado aumenta o desafio das organizações no sentido de desenvolver e utilizar instrumentos de gestão que Ihes garantam um certo nível de competitividade atual e futuro. 


\begin{tabular}{|c|c|c|c|}
\hline Década & Perfil profissionais & Pressupostos & Visão estratégica \\
\hline 30 & Empresários & Fascismo - tirania & $\begin{array}{l}\text { "manda quem pode, } \\
\text { obedece quem tem } \\
\text { juízo" foco resultados }\end{array}$ \\
\hline 40 & $\begin{array}{l}\text { Advogados, especialistas } \\
\text { em entender as leis para } \\
\text { driblá-las }\end{array}$ & $\begin{array}{l}\text { Getúlio Vargas promulga a CLT, } \\
\text { inspirada na carta fascista de } \\
\text { Mussolini. }\end{array}$ & $\begin{array}{l}\text { Primeiras juntas } \\
\text { trabalhistas e as } \\
\text { primeiras reclamações } \\
\text { trabalhistas }\end{array}$ \\
\hline 50 & Engenheiros. & $\begin{array}{l}\text { Recursos Humanos não são } \\
\text { pessoas, mas sim processos } \\
\text { Taylor e Fayol são os gurus da } \\
\text { época. }\end{array}$ & $\begin{array}{l}\text { Fase de } \\
\text { industrialização } \\
\text { do País- RH: estudos } \\
\text { de tempo e movimento }\end{array}$ \\
\hline 60 & Sindicatos & década perdida & Trabalho em equipe \\
\hline 70 & $\begin{array}{l}\text { Administradores de } \\
\text { Empresas }\end{array}$ & $\begin{array}{l}\text { O poder era medido pelo tamanho } \\
\text { da estrutura que tinham para } \\
\text { gerenciar, }\end{array}$ & $\begin{array}{l}\text { Imensos } \\
\text { organogramas } \\
\text { das corporações }\end{array}$ \\
\hline 80 & Psicólogos & $\begin{array}{l}\text { Foco nas pessoas como recursos } \\
\text { mas incapaz de lidar com } \\
\text { processos, leis e sindicatos ao } \\
\text { mesmo tempo. }\end{array}$ & $\begin{array}{l}\mathrm{RH} \text { revolucionário, foco } \\
\text { nos parceiros internos } \\
\text { e acionistas }\end{array}$ \\
\hline 90 & $\begin{array}{l}\text { Década das fusões, } \\
\text { aquisições e } \\
\text { terceirizações }\end{array}$ & $\begin{array}{l}\text { Outplacement para minimizar os } \\
\text { efeitos das demissões. } \\
\text { Comprometimento e a } \\
\text { credibilidade da área ficam } \\
\text { abalados. }\end{array}$ & $\begin{array}{l}\text { metodologias para } \\
\text { integrar as pessoas, } \\
\text { aliviar o stress, testar } \\
\text { os limites }\end{array}$ \\
\hline $\begin{array}{l}1 \text { a } \\
\text { década } \\
\text { séc.XXI }\end{array}$ & $\begin{array}{l}\text { Psicólogos, substituição } \\
\text { de profissionais por } \\
\text { estagiários }\end{array}$ & RH Estratégico & $\begin{array}{l}\text { Foco em resultados e } \\
\text { redução de custos } \\
\text { salariais }\end{array}$ \\
\hline $\begin{array}{l}\text { Próxima } \\
\text { década }\end{array}$ & $\begin{array}{l}\text { Antropólogos, engenheiros } \\
\text { ou profissionais de } \\
\text { processos; equipes } \\
\text { multidisciplinares }\end{array}$ & $\begin{array}{l}\text { Quando o consumidor é } \\
\text { confrontado com uma inovação, } \\
\text { ele reconhece e se encanta }\end{array}$ & Inovação \\
\hline
\end{tabular}

Quadro 1 - Evolução histórica Gestão de Pessoas no Brasil

Elaborado pela autora com base na exposição de Osso (2008)

Nos dias atuais foram apresentadas várias propostas para inovações no modelo de gerir pessoas de forma que a empresa possa auferir diferencial competitivo.. Brandão e Guimarães (2001) citam como propostas a gestão estratégica de recursos humanos (Taylor, Beechler e Napier, 1996); gestão de competências (Prahalad e Hamel, 1990; Heene e Sanchez, 1997); acumulação do saber (Arrègle,1995; Wright, Van e Bouty, 1995) e gestão do capital intelectual (Stewart, 1998). Os autores destacam que essas proposições tem em comum o 
reconhecimento de que as pessoas se constituem num recurso determinante do sucesso organizacional, uma vez que para que a organização possa enfrentar as ameaças e oportunidades de mercado necessitará de profissionais altamente capacitados e aptos para Ihe conferir vantagem competitiva..

No trabalho realizado por Demo (2008) o conceito de competências aparece como referencial para a gestão de carreiras e da política de treinamento e desenvolvimento. A autora enfatiza em suas conclusões que a elaboração e a reavaliação do modelo de gestão de pessoas deve ser considerada tarefa permanente do gestor estratégico das organizações.

No tópico a seguir serão discutidos os conceitos e expostas algumas dificuldades que envolveram a implantação da Gestão de Desempenho.

\subsection{Gestão de desempenho}

Segundo Dutra (2004) a avaliação de desempenho possibilita acompanhar o indivíduo sob três aspectos o desenvolvimento, o esforço e o comportamento. O desenvolvimento determina a expectativa da organização sobre seu desempenho; 0 esforço representa a qualidade de sua entrega à empresa, de acordo com a motivação e as condições ambientais oferecidas pela empresa; e, o comportamento pode ou não afetar o desenvolvimento e o esforço da pessoa, mas com certeza, afetará 0 ambiente organizacional e o desenvolvimento e o esforço de outras pessoas.

Brandão e Guimarães (2001) verificaram em suas pesquisas que a avaliação de desempenho desde a antiguidade foi utilizada para controle dos trabalhadores, mas com o advento do capitalismo e da industrialização ganhou mais significado. Taylor, por exemplo, desenvolveu escalas de avaliação do mérito que quando aplicadas disciplinavam o trabalhador e interferiam na realização do trabalho. Ao longo do século XX, devido a necessidade de instrumentos para motivação do trabalhador ou para reforçar atividades positivas as técnicas de avaliação de desempenho foram aperfeiçoadas com a contribuição das Ciências Sociais. Assim, é importante revisar o conceito de avaliação que os autores sintetizam como sendo uma comparação 
entre o que se espera do indivíduo em termos de realização do trabalho e a sua atuação efetiva (trabalho realizado) e também um mecanismo que permita acompanhar e corrigir os desvios para assegurar a execução. O termo gestão envolve planejamento, acompanhamento e avaliação propriamente dita. Assim, a gestão de desempenho permite rever estratégias, objetivos, processos de trabalho e políticas de recursos humanos.

Azar (1995) citado por Ruas (2003) afirma que a atenção dos psicólogos industriais e organizacionais por muito tempo focou a habilidade cognitiva como um preditor do desempenho no trabalho. De acordo com essa visão, quanto mais inteligente a pessoa, maior a sua possibilidade ser bem sucedida. Os pesquisadores, entretanto, afirmam que o desempenho no trabalho está mais ligado à personalidade do trabalhador que a inteligência. Essa contribui apenas para uma parte dos resultados, ao passo em que a criatividade, liderança, integridade, dedicação e cooperação são fundamentais para o desempenho no trabalho.

Oliveira- Castro, Lima e Veiga (1996) compilaram no Quadro 2, as diversas variáveis capazes de impactar o desempenho no trabalho, indicando a necessidade de se ampliar a busca da fonte dos problemas de desempenho.

\begin{tabular}{|c|c|c|}
\hline Características Organizacionais & Ambiente de tarefas & $\begin{array}{l}\text { Características do } \\
\text { trabalhador }\end{array}$ \\
\hline $\begin{array}{l}\text { Cultura e clima } \\
\text { Políticas de benefícios } \\
\text { Políticas e práticas de } \\
\text { treinamento e desenvolvimento de } \\
\text { pessoal } \\
\text { administração de pessoal } \\
\text { Imagem da organização }\end{array}$ & $\begin{array}{l}\text { Qualidade e disponibilidade de } \\
\text { materiais e equipamentos } \\
\text { Qualidade de comunicação e } \\
\text { relacionamento interpessoal no } \\
\text { grupo de trabalho } \\
\text { Características e escopo do } \\
\text { trabalho } \\
\text { Clareza de objetivos } \\
\text { Adequação de prazos } \\
\text { Qualidade de gerenciamento de } \\
\text { desempenho }\end{array}$ & $\begin{array}{l}\text { Habilidades } \\
\text { Conhecimentos } \\
\text { Atitudes } \\
\text { História funcional } \\
\text { Idade } \\
\text { Sexo } \\
\text { Escolaridade } \\
\text { Motivações } \\
\text { Personalidade }\end{array}$ \\
\hline
\end{tabular}

Quadro 2: Fatores que podem afetar o desempenho no trabalho

Fonte: Oliveira-Castro, Lima e Veiga (1996: 44) 
A existência de diversos fatores que influenciam o desempenho no trabalho se constitui num desafio para a criação de sistemas que avaliem o desempenho do indivíduo na organização de maneira eficaz. Diversos investigadores estudados por Tenbrunsel e outros (1996) citados por Ruas (2003) analisaram as estruturas cognitivas envolvidas nos processos de avaliação de desempenho, enquanto que outros autores vinculam a avaliação de desempenho às pesquisas atitudinais, resultando em análises da influência das avaliações e de feedback sobre as atitudes. Diversos problemas relacionados com a avaliação de desempenho foram identificados por Ruas (2003), como, por exemplo, o efeito halo, a leniência, problemas na comunicação avaliador-avaliado, dentre outros.

A necessidade de mudança no sistema de mensuração de desempenho resultou das mudanças que ocorreram nas organizações - fazendo com que as hierarquias funcionais (com ênfase em controle) passassem a equipes multifuncionais (mais rápidas e horizontais). Assim, o sistema de mensuração com base em resultados financeiros foi substituído por um sistema de avaliação de desempenho com indicadores montados pelas próprias equipes, possibilitando o retorno de informações mais adequadas para a melhoria de desempenhos (Meyer, 2000, citado por Ruas, 2003).

Mas havia uma dificuldade gerencial em abandonar os indicadores financeiros ,então Kaplan e Norton (2000) criaram o Balanced Scorecard (BS), que junta os indicadores financeiros com os três conjuntos de indicadores operacionais, proporcionando uma visão rápida e abrangente da organização, pois, os primeiros demonstram os resultados de ações passadas enquanto os últimos que incluem: satisfação dos clientes, processos internos e capacidade da organização de aprender e melhorar, impulsionam o desempenho futuro. Com isso espera-se que a organização esteja centrada na estratégia e na visão de forma que todos estejam procurando agir da melhor maneira possível para o alcance dos objetivos.

Assim, na persistente busca por um modelo que atenda às expectativas das organizações e de seus empregados, surge como alternativa a Gestão de Competências a ser tratada no próximo segmento. 


\subsection{Gestão de competências}

Conforme relato de Farah (2008), a utilização do termo competências tem seu marco histórico em 1973 com a publicação do artigo Testing for competence rather than for intelligece, de autoria de David McClelland, onde o autor defende o uso de testes de competência para substituir os testes de aptidão e inteligência usados na avaliação de estudantes e na seleção de candidatos sustentando que os testes de competência devem ser teste de desempenho pautados em referenciais amostras de comportamento no trabalho, como por exemplo, quando queremos saber se uma pessoa é capaz de dirigir um automóvel, aplicamos um teste de direção, não um teste de inteligência.

A palavra competência, entretanto, é polissêmica tanto na academia como no campo educacional apresentando variadas conotações e conforme o campo de estudo gera diversas interpretações. Por exemplo, no campo da Psicologia, é entendida como aptidões, habilidades ou capacidades; no campo científico social é vista como conteúdos particulares das diversas qualificações nas organizações do trabalho. Mas, conforme relatam Brandão e Guimarães (2001) foi no surgimento de gestão de pessoas com base no conceito de competência que o termo competência adquiriu diferentes conotações. Assim, torna-se necessário compreender e aprofundar os diferentes sentidos apreendidos de forma a se obter a real apropriação do termo. Para Ruas (2003), competência pode ser definida como o exercício efetivo da capacidade. Amaral et al (2008) consideram competência no sentido de qualificar a pessoa apta a realizar no presente sua atividade com maestria, tendo para tanto suficientes conhecimentos, habilidades e atitudes. A partir dessa definição, os autores ressaltam a amplitude do termo, assim composto por aspectos intelectuais, emocionais e morais, todos importantes para o desempenho adequado das funções. Esclarecem, no entanto, que não se deve atribuir ao indivíduo o adjetivo competente ou incompetente, uma vez que esses designam estados e não situações imutáveis. Das diversas conceituações encontradas, vale destacar a visão de Fleury e Fleury (p.188, 2001) para quem competência deve ser entendida como: "um saber agir responsável e reconhecido, que implica mobilizar, integrar, transferir conhecimentos, recursos e habilidades, que agreguem valor econômico à organização e valor social 
ao indivíduo." Esses autores elaboraram o Quadro 3, inspirados na obra de Lê Boterf onde são apresentadas as definições para os verbos expressos nesse conceito.

\begin{tabular}{|c|c|}
\hline Saber agir & Saber o que e por que faz. Saber julgar, escolher, decidir. \\
\hline $\begin{array}{l}\text { Saber mobilizar } \\
\text { recursos }\end{array}$ & Criar sinergia e mobilizar recursos e competências. \\
\hline Saber comunicar & $\begin{array}{l}\text { Compreender, trabalhar, transmitir informações, } \\
\text { conhecimentos. }\end{array}$ \\
\hline Saber aprender & $\begin{array}{l}\text { Trabalhar o conhecimento e a experiência, rever modelos } \\
\text { mentais; saber desenvolver-se. }\end{array}$ \\
\hline $\begin{array}{l}\text { Saber engajar-se e } \\
\text { comprometer-se }\end{array}$ & Saber empreender, assumir riscos. Comprometer-se. \\
\hline $\begin{array}{l}\text { Saber assumir } \\
\text { responsabilidades }\end{array}$ & $\begin{array}{l}\text { Ser responsável, assumindo os riscos e conseqüências de } \\
\text { suas ações e sendo por isso reconhecido. }\end{array}$ \\
\hline Ter visão estratégica & $\begin{array}{l}\text { Conhecer e entender o negócio da organização, o seu } \\
\text { ambiente, identificando oportunidades e alternativas. }\end{array}$ \\
\hline
\end{tabular}

Quadro 3: Competências para o Profissional

Fleury e Fleury (2001)

Quando se pensa nas competências dos indivíduos que integram uma empresa, podemos vê-la como uma carteira de competências. Para Brandão e Guimarães (2005) a Gestão por Competências se propõe a orientar esforços para planejar, captar, desenvolver e avaliar as competências necessárias à consecução dos objetivos organizacionais, nos seus diferentes níveis, individual, grupal e organizacional. Já Ubeda e Santos (2008) compreendem a gestão de competências como uma prática que procura integrar conhecimento acumulado com a prática dos processos de trabalho ao longo do tempo, demonstrando-se como um modelo dinâmico importante para ser integrado às estratégias empresariais.

Na gestão de competências, o contexto de trabalho e as situações de aprendizagem propiciam o desenvolvimento de competências das pessoas, atestam Fleury e Fleury (2001), agregando valor não só ao individuo, mas também para a organização. Para 
Brandão e Guimarães (2001), identificar as competências individuais equivale a reconhecer o papel da avaliação de desempenho no monitoramento dos fatores humanos desenvolvidos nos processos de trabalho necessários ao alcance dos objetivos organizacionais.

Entretanto, Brandão (2009) constatou críticas à adoção dos modelos de gestão baseados no conceito de competências. Dentre as críticas relatadas pelo autor destacam-se as seguintes bem como seus contra-argumentos:

a) alguns autores acreditam que essa adoção faça parte de uma estratégia organizacional para evitar as reivindicações coletivas, uma vez que esses modelos promovem a individualização do trabalho. Entretanto, Brandão (2009) rebate com o esclarecimento de que ao contrário, a gestão por competências assume como pressuposto de que a competência se manifesta nos diferentes níveis organizacionais, de forma que o indivíduo depende do coletivo e vice-versa.

b) Para outros parece que o modelo agrava problemas de ordem social visto que pode gerar insegurança ou exclusão no emprego o que é .rebatido por Brandão (2009) ao argumentar que ao contrário a Gestão por Competências pode promover a inclusão daqueles que hoje possuem baixa qualificação ao Ihes oferecer orientação e oportunidades de aprimoramento profissional.

No tópico a seguir serão tratados os conceitos concernentes à Gestão de Desempenho baseada nas competências, modelo resultante da junção entre os pressupostos das Gestão de Desempenho e Gestão de Competências.

\subsection{Gestão de desempenho baseada nas competências}

Nos últimos anos, diversas organizações tem tentado encontrar ferramentas de gestão de desempenho que integrem estratégia, aprendizagem, competências e indicadores quantitativos e qualitativos, constataram Brandão et al (2008) em suas pesquisas. De acordo com Dutra (2004), a utilização do conceito de competência propiciou a construção de um modelo de gestão de pessoas mais alinhada com as expectativas do corpo funcional e com as estratégias organizacionais. 
Brandão e Guimarães (2001) aliam o interesse recente pela gestão estratégica de pessoas à origem de uma série de teorias e práticas de recursos humanos. Isso explica porque conceitos como o de competência, desempenho e empregabilidade passaram a integrar a linguagem de muitas organizações, assumindo diferentes sentidos e utilizados, muitas vezes, de maneiras distintas tanto no ambiente empresarial como no meio acadêmico.

Em razão dessa diversidade de conceitos e interpretações, observa-se a gestão de competências e a gestão de desempenho inseridos de forma fragmentada nesses contextos, apesar da evidente relação de interdependência entre elas. Mais do que interdependentes entre si, no entendimento dos autores, elas se complementam num contexto mais amplo de gestão organizacional. Assim, os autores defendem a utilização do termo gestão de desempenho baseada nas competências para denominar essa integração, que dessa forma envolve as atividades de planejamento, acompanhamento e avaliação de desempenho, a partir de um diagnóstico das competências essenciais à organização, desde o nível corporativo até $\mathrm{o}$ individual. $\mathrm{E}$ propõem como desafio que as organizações utilizem a esse modelo em conjunto com práticas de aprendizagem coletiva, desenvolvimento de equipes, dentre outras, que proporcionem oportunidades de crescimento profissional e estimulem as pessoas a desenvolver coletivamente competências e também a compartilhá-las.

Por outro lado, Medeiros et al (2003) ao revisarem a literatura sobre Comprometimento constataram nos estudos de Rocha e Bastos, 1999, que o comprometimento é fator importante para o sucesso na implementação das mudanças organizacionais. E é sobre o estudo dessa variável que se dedica o tópico seguinte.

\subsection{Comprometimento no Trabalho}

Veiga (2008) constatou crescente interesse pelo estudo do comprometimento na literatura nacional e exterior. Medeiros et al (2003) relatam que eram poucos os 
trabalhos sobre comprometimento organizacional do Brasil, em 1992, quando Bastos, apresentou seu artigo no XVI Encontro Anual da Associação Nacional dos Programas de Pós-Graduação em Administração - ENANPAD. A partir daí, Bastos tornou-se referência indispensável nesse assunto para os estudantes e pesquisadores do país. Com essa repercussão, na década que se seguiu, conforme levantamento de Medeiros et al (2003) havia sólida pesquisa na área. A partir dos anos 70, conforme Bastos, Brandão e Pinho (1996), enfatizava-se especialmente a influência do comprometimento organizacional no alcance dos objetivos organizacionais. Dentre os focos dos estudos estava também a busca pelo consenso sobre o sentido da palavra comprometimento, em vista da redundância, ambiguidade e imprecisão dos conceitos apontados por Bastos (1994-conceitos), bem como a existência de outros termos utilizados para descrever o fenômeno, tais como identificação, envolvimento, attachment, saliência e centralidade. Medeiros et al (2003) revelam que na década de 1993-2003, as pesquisas abordaram o comprometimento como um construto multidimensional e procuravam entender os indivíduos e seu vínculo com a organização de uma forma mais complexa.

Quanto à conceituação sobre comprometimento, Bastos, Brandão e Pinho (1997) apresentam-na em dois blocos considerando a linguagem cotidiana ou científica. $\mathrm{Na}$ linguagem cotidiana são identificados com mais freqüência os seguintes usos: $1^{\circ}$ ) comprometimento é um conceito quase próximo de compromisso, envolvimento, e antônimo de descompromissadamente. Indicaria o grau de atenção da pessoa ao realizar algo. $2^{\circ}$ ) comprometimento significa estado do indivíduo de lealdade a algo, que pode ser descrito por sentenças que delineiam intenções, sentimentos. $3^{\circ}$ ) comprometimento está relacionado às condições que conduzem. a produtos indesejados como prejudicar, impedir. Na linguagem científica, o conceito conserva apenas o significado de engajamento, adesão, forte envolvimento do indivíduo com variados aspectos do seu trabalho, em especial com a organização onde trabalha. Os autores alertam que apesar de utilizado para descrever dimensões valorativas opostas, o termo comprometimento encerra em si a noção de algo que amarra, ata, une o indivíduo a alguma coisa.

Numa retrospectiva histórica Bastos e Costa (2001) relembram que Comprometimento no Trabalho, ainda que sob diferentes denominações, sempre fez parte do universo organizacional como requisito de bom desempenho, eficiência e 
eficácia individuais e organizacionais. E, devido a essa centralidade, a partir dos anos noventa a pesquisa sobre comprometimento no trabalho ganhou força principalmente para a análise das relações indivíduo-organização. Depois dessa explicitação, os autores apresentam as dimensões de significados comuns nas definições de Comprometimento Organizacional, tais como o desejo de permanecer; o sentimento de orgulho por pertencer; a identificação, o apego, o envolvimento com objetivos e valores; engajamento, exercer esforço, empenho em favor de. Num passo mais adiante os autores levantam a problemática que gira em torno do conceito de Organização. Reichers (1985) apud Bastos, Brandão e Pinho (1997) pressupõe que para os empregados a organização é uma abstração, representada na verdade, pelos segmentos que a constitui, como por exemplo, a cúpula gerencial, o grupo de trabalhadores: colegas, os clientes, os sindicatos, enfim grupos e indivíduos que coletivamente integrem a organização. Importante notar que esses segmentos nem sempre partilham os mesmos objetivos e valores. Portanto, ao responder uma escala seria interessante obter do indivíduo a representação da organização que o está guiando nas respostas ou que indique 0 aspecto determinante do nível de comprometimento que ele se atribui.

Neste trabalho, a exemplo de Borges et al (2004) adota-se a conceituação de Bastos (1994) para quem comprometer-se implica sentimento de lealdade em relação a algo. Comprometimento organizacional, segundo Bastos (1994) se relaciona com as ofertas da organização que possibilitem oportunidade de desenvolvimento pessoal e profissional. Bastos (1994) considera ainda o comprometimento no trabalho como multidimensional e que pode se manifestar em três focos: a profissão, o sindicato e a organização. A interpretação de Morais, Godoi e Batista (2004) destaca a utilização de comprometer-se no sentido de sentir-se vinculado a algo e ter desejo de permanecer naquele curso de ação, conforme definido por (BASTOS, 1997). Para esses autores o indivíduo comprometido se identifica e adere aos objetivos e valores da organização e para isso é capaz de se esforçar para ir além do que a sua função exige. Assim comprometimento organizacional significa adesão, forte envolvimento do indivíduo com as rotinas de trabalho.

Ao se tratar de modelos de conceituação, dentre os diversos apresentados, o que obteve maior aceitação dentre os pesquisadores, inclusive a nível internacional, é o 
modelo em três dimensões estabelecido por Meyer e Allen (1993). No Brasil o modelo foi validado por Medeiros e Enders (1998), conceituando o comprometimento organizacional nas dimensões Afetivo, Instrumental e Normativo. O Comprometimento Afetivo é aquele onde se observa uma identificação com os objetivos e valores da organização. Envolve uma relação em que o indivíduo almeja dar algo de si para contribuir com o sucesso da organização. $O$ empregado que apresenta forte comprometimento afetivo permanece na organização porque quer.O comprometimento instrumental é percebido como altos custos associados a deixar a organização. Nesse tipo de vínculo o indivíduo permanece na organização porque precisa. Finalmente, o Comprometimento normativo é identificado na obrigação em permanecer na organização. Esse tipo de vínculo revela que o indivíduo permanece na organização porque sente que é obrigado.

Bastos (2002) constatou que naquela época geralmente a pesquisa sobre comprometimento estabelecia relações entre variáveis pessoais, características do trabalho e políticas organizacionais com diferentes níveis de vínculo do trabalhador, mas que faltavam estudos para comparar a intensidade e a natureza desse vínculo entre diferentes tipos de organizações. Assim, com objetivo de preencher a lacuna detectada, Bastos (2002) realizou um estudo com base no interesse de compreender o comprometimento do trabalhador com facetas de seu mundo de trabalho, considerando algumas inovações organizacionais, dentre as quais o modelo Just in time e Qualidade Total. Para tanto recorreu ao tratamento simultâneo do comprometimento com a carreira, a organização e o sindicato dado na pesquisa de Bastos (1994), e sintetizou os resultados no Quadro 4.

Nesse Quadro, o caso A representa a situação clássica de uma organização burocrática que se encontrava fechada a quaisquer transformações semelhantes às de organizações mais dinâmicas ou de setores mais competitivos da economia. Os casos $B, C$ e $D$ foram selecionados pelo fato de aderirem às ferramentas e soluções gerenciais do período pós-fordista, e por apresentarem iniciativas de ajuste congruentes com as transformações atuais do mundo do trabalho, em graus e modalidades diferenciadas.

$O$ caso $B$, trata-se de uma pequena empresa privada do setor metalúrgico, que adotou como premissa a organização do trabalho que busca flexibilidade segundo o 


\begin{tabular}{|c|c|c|c|}
\hline $\begin{array}{l}\text { A- Administração pública } \\
\text { direta }\end{array}$ & $\begin{array}{l}\text { B- Empresa } \\
\text { metalúrgica }\end{array}$ & C- Fundação de saúde & $\begin{array}{l}\text { D-Empresa de } \\
\text { telecomunicação }\end{array}$ \\
\hline $\begin{array}{l}\text { - Baixo comprometimento } \\
\text { organizacional } \\
\text { - Predominância de } \\
\text { "descomprometidos" } \\
\text { - Maior participação de } \\
\text { "comprometidos apenas } \\
\text { com a carreira" } \\
\text { - Presença relativamente } \\
\text { mais alta de } \\
\text { "sindicalistas" e de } \\
\text { "profissionaissindicalistas" }\end{array}$ & $\begin{array}{l}\text { - Alto } \\
\text { comprometimento } \\
\text { organizacional } \\
\text { - Elevada } \\
\text { concentração de } \\
\text { "comprometidos" } \\
\text { - Forte presença de } \\
\text { "localistas" } \\
\text { - Baixo } \\
\text { comprometimento } \\
\text { com o sindicato } \\
\text { - Alto } \\
\text { comprometimento } \\
\text { com a carreira }\end{array}$ & $\begin{array}{l}\text { - Presença forte de } \\
\text { "anti-sindicato" } \\
\text { - Menor contingente de } \\
\text { "comprometidos" entre } \\
\text { os três contextos } \\
\text { inovadores } \\
\text { - Maior contingente de } \\
\text { "descomprometidos" } \\
\text { entre os três } \\
\text { contextosinovadores }\end{array}$ & $\begin{array}{l}\text { - Maior } \\
\text { comprometimento } \\
\text { organizacional } \\
\text { - O mais elevado } \\
\text { contingente de } \\
\text { "comprometidos" } \\
\text { - Mais elevado } \\
\text { comprometimento } \\
\text { com a carreira } \\
\text { - Relativamente mais } \\
\text { alto comprometimento } \\
\text { com o sindicato }\end{array}$ \\
\hline
\end{tabular}

Quadro 4 - Síntese dos resultados comparativos dos padrões de comprometimento nos quatro contextos organizacionais

Fonte: Bastos (2002)

modelo Just in Time. O caso $\mathrm{C}$ refere-se a uma fundação privada que mantém duas prestadoras de serviços de saúde, revelando forte preocupação com a qualidade de serviços; O caso D, por sua vez, trata-se de uma empresa de economia mista, prestadora de serviços de telecomunicações ., implementação do Programa de Qualidade Total. Bastos (2002) encontrou resultados que demonstram relação de congruência entre as características dos contextos estudados e os padrões de comprometimento identificados.

$\mathrm{Na}$ organização burocrática, caso $\mathrm{A}$, os padrões de comprometimento se revelaram bem mais frágeis, enquanto que nos três contextos inovadores, casos $B, C$ e $D$, apesar de terem indicadores mais positivos, não se caracterizam de forma homogênea quanto aos padrões de comprometimento. Portanto, não foi encontrado o nível positivo de comprometimento com os três focos estudados, a exemplo daquele encontrado no padrão comprometido, esperado nas organizações inovadoras.

Outra conclusão do autor versa sobre o fato de que o exame das organizações selecionadas agrega evidências que possibilitam compreender os determinantes dos padrões de comprometimento identificados. O impacto do contexto de trabalho no comprometimento do trabalhador tornou-se evidente pelas diferenças encontradas no peso dos diferentes padrões entre as organizações são suficientemente fortes e destacam o impacto do contexto de trabalho no comprometimento do trabalhador. Contudo, o autor acredita que mecanismos de seleção, avaliação, treinamento e 
marketing interno podem explicar parte da associação encontrada, não se podendo atribuí-la exclusivamente aos aspectos da organização do trabalho e das políticas organizacionais inovadoras que diferenciam os casos selecionados. Enfim, suas evidenciam a carência de dados sobre possíveis associações entre mudanças organizacionais e comprometimento no trabalho. 


\section{MÉTODOS E TÉCNICAS DE PESQUISA}

De acordo com Zanella (2009) a pesquisa pode ser dividida em dois grandes grupos: a pesquisa científica pura também denominada teórica, em que os pesquisadores articulam conceitos, e a pesquisa científica aplicada que se dedica a gerar soluções para os problemas humanos.

Esta pesquisa, valendo-se da taxonomia de Triviños (1987 apud ZANELLA, 2009) pode ser classificada quanto ao tipo de estudo como descritiva, visto ter como finalidade conhecer a realidade a respeito da aplicação dos conceitos de competências e comprometimento no trabalho, suas características e seus problemas.

De acordo com a taxonomia de Mattar (1999 apud ZANELLLA, 2009) com relação à natureza das variáveis pesquisadas é uma pesquisa quantitativa quando se pretende medir e quantificar os resultados da investigação, agrupando-os em dados estatísticos.

\subsection{Caracterização do setor ${ }^{1}$}

A organização objeto de estudo aqui identificada pelo nome fictício BANESTIL, é uma instituição bancária pública de grande porte. No quadro de colaboradores, as mulheres representam $41 \%$ do total e ocupam cerca de $38 \%$ das vagas destinadas aos cargos de confiança.

Observando-se o fator idade, a estratificação apresenta 8\% com 25 anos de idade, $35 \%$ na faixa de 26 a 35 anos, $30 \%$ na faixa de 36 a 45 anos e $27 \%$ com idade acima de 45 anos.

Com relação ao fator tempo de serviço, apresenta baixa rotatividade, e a seguinte composição: $40 \%$ até 5 anos de serviço, 20\% de 6 a 10 anos, 2\% de 11 a 15 anos,

\footnotetext{
${ }^{1}$ Omitidos os dados e informações que possibilitem a identificação da Instituição pesquisada uma vez que não foi obtida a autorização formal para efetivação da pesquisa.
} 
$3 \%$ de 16 a 20 anos, $20 \%$ de 21 a 25 anos e $15 \%$ acima de 25 anos.

A instituição considera que estimula os colaboradores a construírem sua carreira, o que pode ser deduzido dos seguintes dados que fornece a respeito do nível de escolaridade: $0,05 \%$ dos colaboradores estão no nível fundamental, 30\% concluíram o ensino médio, 45\% concluíram o ensino superior e $24,5 \%$ possuem Especialização, Mestrado ou Doutorado.

\subsection{Amostra $^{2}$}

A amostra resultante da aplicação da pesquisa se constitui de trinta respondentes lotados em setores diversos da Empresa BANESTIL. Sendo que vinte e um respostas foram coletadas pessoalmente e nove por e-mail. A maioria dos respondentes, cerca de $65 \%$, é do sexo masculino e $97 \%$ do total ocupam cargo comissionado. O tempo de serviço está compreendido no intervalo de 2 a 29 anos de trabalho, com uma freqüência de 17 anos, sendo 50\% com menos de 10 anos de trabalho. Quanto ao item escolaridade, 20\% possuem o nível médio, 60\% possuem especialização, 10\% mestrado e 10\% doutorado. Quanto às idades, variam entre 27 a 55 anos, com uma freqüência de $80 \%$ na faixa até 48 anos.

\subsection{Caracterização dos instrumentos de pesquisa}

O Instrumento de coleta de dados trata-se de um questionário estruturado, formulado com base nos instrumentos de coleta utilizados por Marchioro (2007), Lazzari (2007) e Garcia (2007). O instrumento, conforme consta no Apêndice A, foi seccionado em quatro partes, a saber:

\footnotetext{
${ }^{2}$ Omitidos os dados e informações que possibilitem a identificação da Instituição pesquisada uma vez que não foi obtida a autorização formal para efetivação da pesquisa.
} 


\section{PARTE}

Destinada a colher os dados biográficos e profissionais para caracterização da amostra.

\section{PARTE}

Constituída por dez itens com cinco alternativas de respostas: discordo plenamente, discordo, em dúvida, concordo, concordo plenamente.

Os itens foram retirados do instrumento de pesquisa utilizado por Marchioro (2007), um questionário que foi elaborado utilizando como referência os principais objetivos propostos pela Gestão de Desempenho Baseada nas Competências. Originalmente o questionário contém 11 questões do tipo fechadas, mas para a presente pesquisa foram feitas as alterações constantes no Quadro 5.

\begin{tabular}{|c|c|c|c|}
\hline № & ITEM & REFERÊNCIA & ALTERAÇÃO \\
\hline 1 & $\begin{array}{l}\text { Foi bem divulgado e explicado pela } \\
\text { organização? }\end{array}$ & $\begin{array}{l}\text { MARCHIORO, } \\
(2007)\end{array}$ & $\begin{array}{l}\text { EXCLUÍDO E } \\
\text { SUBSTITUÍDO }\end{array}$ \\
\hline 2 & $\begin{array}{l}\text { Auxilia o funcionário no seu desenvolvimento } \\
\text { profissional e planejamento da carreira. }\end{array}$ & $\begin{array}{l}\text { MARCHIORO, } \\
(2007)\end{array}$ & \\
\hline 3 & $\begin{array}{l}\text { Possibilita que seja percebido o entusiasmo, } \\
\text { colaboração e dedicação com que o } \\
\text { funcionário desempenha suas atividades. }\end{array}$ & $\begin{array}{r}\text { LAZZARI (2007), } \\
\text { GARCIA(2007) } \\
\end{array}$ & $\begin{array}{l}\text { SUBSTITUIU } \\
\text { ITEM } 1\end{array}$ \\
\hline 4 & $\begin{array}{l}\text { Auxilia para aumentar o comprometimento do } \\
\text { funcionário com a organização. }\end{array}$ & $\begin{array}{r}\text { MARCHIORO,(2 } \\
007) \\
\end{array}$ & \\
\hline 5 & $\begin{array}{l}\text { Avalia adequadamente as competências e } \\
\text { experiências dos funcionários. }\end{array}$ & $\begin{array}{l}\text { MARCHIORO, } \\
(2007) \\
\end{array}$ & \\
\hline 6 & $\begin{array}{l}\text { Contém informações suficientes para auxiliar } \\
\text { no gerenciamento de equipes. }\end{array}$ & $\begin{array}{l}\text { MARCHIORO, } \\
(2007)\end{array}$ & \\
\hline 7 & $\begin{array}{l}\text { Auxilia na identificação dos funcionários com } \\
\text { competências e experiências necessárias para } \\
\text { atender às necessidades da organização. }\end{array}$ & $\begin{array}{l}\text { MARCHIORO, } \\
(2007)\end{array}$ & \\
\hline 8 & $\begin{array}{l}\text { Valoriza a qualificação dos empregados } \\
\text { facilitando nas situações de reconhecimento do } \\
\text { mérito. }\end{array}$ & $\begin{array}{l}\text { MARCHIORO, } \\
(2007)\end{array}$ & \\
\hline 9 & $\begin{array}{l}\text { Consegue refletir exatamente os pontos } \\
\text { positivos e negativos do funcionário. }\end{array}$ & $\begin{array}{r}\text { MARCHIORO, } \\
(2007) \\
\end{array}$ & \\
\hline 10 & É utilizado como instrumento punitivo? & $\begin{array}{l}\text { MARCHIORO, } \\
(2007\end{array}$ & EXCLUÍDO \\
\hline 11 & $\begin{array}{l}\text { É possível confiar nesse sistema de avaliação } \\
\text { de desempenho. }\end{array}$ & $\begin{array}{l}\text { MARCHIORO, } \\
(2007)\end{array}$ & \\
\hline 12 & Você está satisfeito com a GDPC. & $\begin{array}{r}\text { MARCHIORO, } \\
(2007)\end{array}$ & REDAÇÃO \\
\hline
\end{tabular}

Quadro 5 - Refências para Elaboração Parte II Questionário

Fonte: Autora 
As alterações assinaladas no Quadro são as seguintes:

a) o item 1 do questionário de Marchioro (2007) - "Foi bem divulgado e explicado pela organização?" foi substituído por "Possibilita que seja percebido o entusiasmo, colaboração e dedicação com que o funcionário desempenha suas atividades", por sua vez, retirado dos instrumentos utilizados por Lazzari (2007) e Garcia (2007).

b) o item 10 "É utilizado como instrumento punitivo? foi excluído.

c) A redação do item "Você está satisfeito com a GDPC." foi substituída por "O funcionário está satisfeito com o GDPC".

\section{PARTE}

Constituída pelos dez itens, assinalados no quadro, com cinco alternativas de respostas: discordo plenamente, discordo, em dúvida, concordo e, concordo plenamente. Os dez itens constam no instrumento validado para a realidade brasileira por Medeiros e Enders (1998). Originalmente o instrumento é composto de 18 indicadores distribuídos nas dimensões afetiva, normativa e instrumental do comprometimento organizacional conforme conceituadas por Meyer e Allen, 1991. A seleção dos itens não tomou por base os critérios fatoriais da pesquisa de Medeiros e Enders (1998), entretanto as informações das cargas fatoriais encontradas nas pesquisas dos autores podem favorecer a apresentação dos Resultados, por isso os fatores encontrados por eles encontram-se informados no Quadro 6.

Importante observar que na análise fatorial de Medeiros e Enders (1998), o item "Esta Organização merece a minha lealdade" figura como indicador de comprometimento afetivo para a realidade brasileira, mas na presente pesquisa foi adotada a posição original de Meyer e Allen como indicador de comprometimento normativo.

De acordo com a extração fatorial realizada por Medeiros e Enders (1998), os três fatores possuem um índice de consistência interna, ou alfa de Cronbach aceitáveis, sendo que o primeiro fator, dimensão afetiva, possui um alfa de 0,68; o segundo, dimensão normativa, possui um alfa de 0,70 e o terceiro fator, dimensão instrumental, um alfa de 0,62 .

IV PARTE - constituída de uma questão aberta para que o funcionário fizesse alguma observação sobre a GDPC. 
COMPROMETIMENTO ORGANIZACIONAL

\begin{tabular}{|c|c|c|c|}
\hline \multirow{2}{*}{ INDICADORES } & \multicolumn{3}{|c|}{ FATORES } \\
\hline & Afetivo & Normativo & Instrumental \\
\hline \multicolumn{4}{|l|}{ Comprometimento Afetivo } \\
\hline $\begin{array}{l}\text { Eu realmente sinto os problemas da } \\
\text { organização como se fossem meus. }\end{array}$ & 0,73 & & \\
\hline $\begin{array}{l}\text { Esta organização tem um imenso } \\
\text { significado pessoal para mim. }\end{array}$ & 0,64 & & \\
\hline $\begin{array}{l}\text { Eu seria muito feliz em dedicar o resto da } \\
\text { minha carreira nesta organização. }\end{array}$ & 0,57 & & \\
\hline \multicolumn{4}{|l|}{ Comprometimento Normativo } \\
\hline Eu devo muito a minha organização & & 0,53 & \\
\hline Esta organização merece minha lealdade & & 0,61 & \\
\hline \multicolumn{4}{|l|}{ Comprometimento Instrumental } \\
\hline $\begin{array}{l}\text { Se eu decidisse deixar minha } \\
\text { organização agora, minha vida ficaria } \\
\text { bastante desestruturada }\end{array}$ & & & 0,77 \\
\hline $\begin{array}{l}\text { Eu acho que teria poucas alternativas se } \\
\text { deixasse esta organização. }\end{array}$ & & & 0,70 \\
\hline
\end{tabular}

Quadro 6 - Referências para Elaboração Parte III Questionário

Fonte: Medeiros e Enders (1998) com adaptações feitas pela Autora.

\subsection{Procedimentos de coleta e de análise de dados ${ }^{3}$}

A coleta de dados ocorreu no período de 21/09/2010 a 05/10/2010 e foi realizada de duas formas:

a) Aplicação presencial de vinte e um questionários numa unidade de apoio administrativo ao setor financeiro da Instituição.

b) Aplicação por e-mail, quando os questionários foram enviados a trinta funcionários de lotações diversas.

Os dados coletados foram tabulados em excell e analisados quantitativamente, mediante aplicação das funções para obtenção da média e desvio padrão.

\footnotetext{
${ }^{3}$ Omitidas informações de procedimentos que possibilitem a identificação da Instituição pesquisada em virtude da não obtenção de autorização expressa para efetivação da pesquisa.
} 


\section{RESULTADOS E DISCUSSÃO}

Os dados coletados serão apresentados a seguir, de acordo com a disposição dos itens pesquisados no Questionário. Assim, primeiramente estão as respostas dos itens da II PARTE relativos à percepção dos funcionários acerca da Gestão de Desempenho baseada nas Competências. Para tanto foram reunidos na TABELA 1, dispostos em ordem crescente da média encontrada.

\begin{tabular}{|c|c|c|c|}
\hline Item & média & $\begin{array}{l}\text { Desvio } \\
\text { padrão }\end{array}$ & moda \\
\hline $\begin{array}{l}\text { 1. Auxilia o funcionário no seu desenvolvimento profissional e planejamento } \\
\text { da carreira }\end{array}$ & 3,9 & 0,97 & 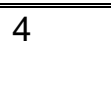 \\
\hline $\begin{array}{l}\text { 6. Auxilia na identificação dos funcionários com competências e } \\
\text { experiências necessárias para atender às necessidades da organização }\end{array}$ & 3,9 & 0,93 & 4 \\
\hline $\begin{array}{l}\text { 3. Auxilia para aumentar o comprometimento do funcionário com a } \\
\text { organização }\end{array}$ & 3,6 & 1,13 & 4 \\
\hline $\begin{array}{l}\text { 7. Valoriza a qualificação dos empregados facilitando nas situações de } \\
\text { reconhecimento do mérito }\end{array}$ & 3,6 & 0,97 & 4 \\
\hline 9. É possível confiar nesse sistema de avaliação de desempenho & 3,6 & 0,93 & 4 \\
\hline 10. O funcionário está satisfeito com o GDPC, & 3,6 & 1,22 & 4 \\
\hline 4. Avalia adequadamente as competências e experiências dos funcionários & 3,5 & 0,93 & 4 \\
\hline $\begin{array}{l}\text { 2. Possibilita que seja percebido o entusiasmo, colaboração e dedicação } \\
\text { com que o funcionário desempenha suas atividades }\end{array}$ & 3,4 & 1,16 & 4 \\
\hline $\begin{array}{l}\text { 5. Contém informações suficientes para auxiliar no gerenciamento de } \\
\text { equipes }\end{array}$ & 3,4 & 0,97 & 4 \\
\hline $\begin{array}{l}\text { 8. Consegue refletir exatamente os pontos positivos e negativos do } \\
\text { funcionário }\end{array}$ & 3,2 & 1,07 & 4 \\
\hline
\end{tabular}

TABELA 1 - Percepção acerca da GDPC: classificação pela média

Fonte: Coleta dados pesquisa

Nota-se que os funcionários percebem uma melhora no seu desenvolvimento profissional como se pode observar pelas respostas no item $1(\mathrm{M}=3,9$, $\mathrm{DP}=0,97)$. Semelhantemente, com base nas respostas do item $6(M=3,9$, DP =0,93) pode-se dizer que os funcionários consideram que o modelo auxilia na identificação das competências individuais que são necessárias às estratégias organizacionais.

Relevante para esta pesquisa foi observar as respostas do item 3, visto referir-se ao comprometimento organizacional, outra variável pesquisada neste trabalho. Se 
observado sob a ótica da moda, poder-se-ia até afirmar que os funcionários concordam que a GDPC contribui para o aumento do comprometimento organizacional. Entretanto a certeza se dissipa quando observada a Média igual a 3,6 com Desvio padrão $=1,3$.

Os dados encontrados no item $2(M=3,4, D P=1,16)$ e $8(M=3,2, D=1,7)$ parecem indicar que na percepção dos funcionários, a GDPC não proporciona aos Gestores a visibilidade necessária para avaliar o seu subordinado.

\begin{tabular}{|c|c|c|c|c|}
\hline No & ITEM & MÉDIA & $\begin{array}{l}\text { DESVIO } \\
\text { PADRÃO }\end{array}$ & MODA \\
\hline .1 & $\begin{array}{l}\text { Eu seria muito feliz em dedicar o resto de } \\
\text { minha carreira nesta organização. }\end{array}$ & 3,5 & 1,3 & 4 \\
\hline 2 & $\begin{array}{l}\text { Eu realmente sinto os problemas da } \\
\text { organização como se fossem meus. }\end{array}$ & 3,3 & 1,3 & 4 \\
\hline 3 & $\begin{array}{l}\text { Eu não me sinto emocionalmente vinculado a } \\
\text { esta organização }\end{array}$ & 2,5 & 1,4 & 1 \\
\hline \multirow[t]{2}{*}{4} & $\begin{array}{l}\text { Esta organização tem um imenso significado } \\
\text { pessoal para mim. }\end{array}$ & 4 & 1,3 & 5 \\
\hline & Comprometimento afetivo & 3,3 & 1,3 & 4 \\
\hline 5 & $\begin{array}{l}\text { Se eu decidisse deixar esta organização agora, } \\
\text { minha vida ficaria bastante desestruturada. }\end{array}$ & 3,3 & 1,3 & 4 \\
\hline 6 & $\begin{array}{l}\text { Eu acho que teria poucas alternativas se } \\
\text { deixasse esta organização. }\end{array}$ & 2,5 & 1,2 & 2 \\
\hline \multirow[t]{2}{*}{7} & $\begin{array}{l}\text { Se já não tivesse dado tanto de mim nesta } \\
\text { organização pensaria em trabalhar noutro } \\
\text { lugar. }\end{array}$ & 2,5 & 1,2 & 2 \\
\hline & Comprometimento instrumental & 2,8 & 1,2 & 2 \\
\hline 8 & $\begin{array}{l}\text { Eu não sinto nenhuma obrigação de } \\
\text { permanecer nesta organização. }\end{array}$ & 3,2 & 1,4 & 2 \\
\hline 9 & Esta organização merece minha lealdade. & 4 & 1,4 & 5 \\
\hline 10 & Eu devo muito a esta organização. & 3,8 & 1,2 & 4 \\
\hline & Comprometimento normativo & 3,7 & 1,3 & - \\
\hline
\end{tabular}

TABELA 2 - Quadro Comprometimento Organizacional

Fonte: coleta dados da pesquisa

A partir deste ponto, são apresentados os resultados da III PARTE do questionário, os quais versam sobre os possíveis sentimentos com relação à organização. Importante relembrar que os cálculos consideraram os valores de 1 a 5 na escala de Likert atribuídos às respostas de acordo com o nível de concordância com os itens. 
Conforme se observa na TABELA, onde se encontram compilados os resultados, quanto ao nível de comprometimento geral, a partir das médias, pode-se inferir que entre os respondentes o nível de comprometimento normativo com média igual a 3,7 (DP $=1,3)$ é superior ao nível de comprometimento afetivo, que apresentou média igual a 3,3 ( $D P=1,3)$. O comprometimento instrumental, por sua vez, apresentou média igual a 2,8 $(\mathrm{DP}=1,3)$. Esses resultados conduzem ao entendimento de que o vínculo mais forte dos funcionários com a organização seria o normativo, ou seja, permanecem na organização porque se sentem obrigados.

Os resultados a seguir dizem respeito à questão aberta da IV PARTE do Questionário, onde os funcionários tiveram liberdade para expressar suas opiniões ou observações adicionais à GDPC. Dez funcionários registram comentários diversos sobre a GDPC. Dentre eles, chama especial atenção o que diz "Como qualquer outro método de avaliação de desempenho, serve mais para não ser punido ou ser punido, que para ajudar na carreira" justamente por se referir ao aspecto punitivo. A curiosidade se deve ao fato de que na elaboração da Parte do Questionário foi retirado o item "É utilizado como instrumento punitivo?".

Em contrapartida, vale registrar um comentário que parece revelar uma aprovação do modelo: "A GDPC, QUANDO O PROCESSO DE AVALIAÇÃO E DE GESTÃO É LEVADO A SÉRIO, É O MELHOR QUE VI NESSA EMPRESA DURANTE OS MEUS 29 ANOS DE TRABALHO."

Em suma, os resultados parecem indicar que os funcionários percebem que a Gestão de Desempenho por Competências auxilia no seu desenvolvimento profissional e planejamento da carreira, mas, estão em dúvida quanto ao aspecto avaliativo do modelo, embora percebam que possa valorizar suas qualificações e reconhecer seus méritos. Constatou-se também uma inclinação para a concordância de que a GDPC contribui para aumentar o comprometimento organizacional. Entretanto, de acordo com a conceitualização de Meyer e Allen, 1991, validada para a realidade nacional por Medeiros e Enders (1998), os resultados da pesquisa revelaram que o comprometimento normativo, prevalece sobre $o$ afetivo e por último o instrumental, ou seja, os funcionários porque se sentem obrigados a permanecer na Empresa. 
Fazendo um paralelo desses resultados com as pesquisas empreendidas com idêntica curiosidade, observa-se quanto à percepção dos empregados acerca da Gestão de Desempenho baseada nas Competências, que Marchioro (2007) encontrou a indicação de satisfação parcial com o GDPC e uma tendência de insatisfação nos itens que avaliam questões individuais tais como competências, experiências, pontos positivos e negativos dos funcionários. Apesar disso, as demais experiências dentre os inúmeros trabalhos subsidiam o posicionamento de que a Gestão de Desempenho baseada nas competências tem se demonstrado um instrumento importante para a identificação e monitoramento das competências humanas, capaz de influenciar a formulação estratégica e o desenvolvimento organizacional (Ubeda e Santos, 2008).

Finalmente, quanto ao comprometimento no trabalho, a pesquisa de Garcia (2007) identificou prevalência do comprometimento afetivo sobre $\mathrm{o}$ instrumental e deste sobre o comprometimento normativo. 


\section{CONCLUSÕES E RECOMENDAÇÕES}

Competência, desempenho e comprometimento são alvos constantes de pesquisas como bem se vê na literatura, na Internet e na Academia.

Brandão e Guimarães (2001) têm inspirado muitos empreendimentos nessa seara e particularmente o presente trabalho que teve como objetivo descrever a percepção dos funcionários de uma instituição bancária pública acerca da gestão de desempenho baseada nas competências e identificar o nível do seu comprometimento no trabalho.

Apesar do alcance desse objetivo, permanecem ainda o questionamento sobre a relação entre a percepção dos funcionários acerca da Gestão de Desempenho por Competências e o comprometimento organizacional, despertado no desenvolvimento e aplicação da pesquisa, visto que à luz da revisão bibliográfica há indícios de que o comprometimento organizacional seja um preditor do desempenho no trabalho, como por exemplo Garcia (2007) constatou que funcionários mais comprometidos apresentam desempenhos mais elevados.

Os resultados parecem indicar que os funcionários percebem a contribuição da Gestão de Desempenho por Competências no seu desenvolvimento profissional, mas, estão em dúvida quanto ao aspecto avaliativo do modelo, embora acreditem que possa valorizar suas qualificações e reconhecer seus méritos. Constatou-se também uma tendência a concordar que a GDPC contribua para o aumento do comprometimento organizacional.

As conclusões ficaram prejudicadas pelas limitações encontradas na realização do trabalho, dentro as quais as medidas de segurança organizacionais, que embora compreensíveis, às vezes são entendidas como barreiras à expansão do conhecimento. De forma que ao término do trabalho se descubra que embora os objetivos propostos tenham sido alcançados resta ainda a sensação do inacabado. Resta sugerir novos empreendimentos nessa direção e ainda que limitado, esperase que esta pesquisa possa contribuir para o enriquecimento dos conceitos e que se constitua mesmo uma provocação para novos estudos sobre o tema. 


\section{REFERÊNCIAS}

AMARAL, R. M.; GARCIA, L. G.; FARIA, L. I..L. e ALIPRANDINI, D. H. Modelo para o mapeamento de competências em equipes de inteligência competitiva. Ci. Inf. [online]. 2008, vol.37, n.2, pp. 7-19.

BASTOS, A. V .B., BRANDÃO, M.G.A. e PINHO, A. P. M. Comprometimento organizacional: .uma análise do conceito expresso por servidores universitários no cotidiano de trabalho. Revista de Administração Contemporânea. v.l. 100 RAC, v.1, n.2, Maio/Ago. 1997 disponível em http://www.scielo.br/pdf/rac/v1n2/v1n2a06.pdfn.2. p. $97-120,1997$ acesso em 06/12/2010.

BASTOS, A. V. B.. Confusão conceitual no estudo de atitudes no trabalho. Temas psicol., Ribeirão Preto, v. 2, n. 3, dez. 1994 . Disponível em $<$ http://pepsic.homolog.bvsalud.org/scielo.php?script=sci_arttext\&pid=S1413$389 \times 1994000300010 \&$ lng=pt\&nrm=iso $>$. acessos em 07 dez. 2010

. Comprometimento no trabalho: os caminhos da pesquisa e os seus desafios teórico-metodológicos, in: Tamayo, A.; Borges-Andrade, J. E.; Codo, W. (org): Trabalho, organizações e cultura (Coletâneas da Anpepp no. 11, pag. 94109). Rio de Janeiro: Associação Nacional de Pesquisa e Pós-graduação em Psicologia. Disponível em http://www.infocien.org/Interface/Colet11.htm acesso em $\underline{09 / 12 / 2010 .}$.

BRANDÃO, H. P.; BAHRY,C.P. Gestão por competências: métodos e técnicas para mapeamento de competências. Rev. Adm. Pública, Abr/Jun 2005, vol.56, no.2, p.875-898.

BRANDÃO, H. P. et al. Gestão de desempenho por competências: integrando a gestão por competências, o balanced scorecard e a avaliação 360 graus. Rev. Adm. Pública, Out 2008, vol.42, no.5, p.875-898.

BRANDÃO, H. P.; GUIMARÃES, T. A. Gestão de competências e gestão de desempenho: tecnologias distintas ou instrumentos de um mesmo construto? Revista de Administração de Empresas (FGV), v.41, n.1, p.8-15, 2001.

BRITO, L.M.; CARLOS, L.M.P; AVELINO, F.A. de M. Gestão de Competências: como os empregados percebem este modelo de gestão? Revista de Ciências da Administração. v. 9, n. 18, p. 56-79, mai./ago. 2007 
DEMO, G. Políticas de Gestão de Pessoas nas Organizações: Papel dos Valores Pessoais e da Justiça Organizacional. 2.ed. São Paulo: Atlas, 2008.

DUTRA, J.S. Competências: conceitos e instrumentos para a gestão de pessoas na empresa moderna. São Paulo: Atlas, 2004.

FARAH, F. O conceito de competência: Gestão de Carreira, Coaching e Mentoring. Publicado em 17/08/2008. Disponível em:

http://www.gestaodecarreira.com.br/coaching/carreira/o-conceito-decompetencia. html Acesso em 27/3/2010.

FLEURY, M.T.L; FLEURY,A. Construindo o Conceito de Competência. RAC, vol.5 Edição Especial p.183-196, 2001.

FONSECA, C.A.M., BASTOS, A.V.B. Criatividade e comprometimento organizacional: suas relações com a percepção de desempenho no trabalho. RPOT vol.3 - no 1 - jan/jun 2003 - p. 61-88.

GARCIA, C. de A.N. Relação entre comprometimento organizacional e o desempenho no trabalho. UFRGS, 2007. Monografia Disponível em www.lume.ufgrs.br/bitstream/handle/10183/13904/000649632.pdf?.sequence $=1$

GUIMARÃES, T. A. A Nova Administração Pública e a Abordagem da Competência. RAP, v.34, n.3, p.125-140, 2000.

LAZZARI, J. Percepção dos funcionários da GEREL Curitiba sobre a avaliação de desempenho por competências. Especialização em Negócios Financeiros. Orientador: Prof.Roberto Lima Ruas. UFRGS, 2007.

LODI, Q. Gestão de Desempenho por Competências como ferramenta de Gestão de Pessoas no Banco do Brasil S/A - Ag de Dois Vizinhos (PR) UFGRS, 2007. Disponível em www.lume.ufgrs.br/handle/10183/14173.

MARCHIORO, I.M. Gestão de Desempenho Profissional por Competências do Banco do Brasil: A percepção dos funcionários da Agência Empresarial Curitiba Sul/PR. Especialização em Negócios Financeiros. Orientador: Prof. a Cláudia Simone Antonelo. UFRGS, 2007 Disponível em www.lume.ufgrs.br/handle/10183/14024. 
MEDEIROS, C. A F., ENDERS, W. T.Validação do Modelo de Conceitualização de Três Componentes do Comprometimento Organizacional (Meyer e Allen, 1991) RAC, v.2, n.3, Set./Dez. 1998. Disponível em:

http://www.scielo.br/pdf/rac/v2n3/v2n3a05.pdf acesso em 04/12/2010

MEDEIROS, C. A F., ALBUQUERQUE, L. G., SIQUEIRA. M. e MARQUES, G. M. Comprometimento organizacional: o estado da arte da pesquisa no Brasil. Anais do ENANPAD, cor.1551. Salvador, 2002. RAC, v. 7, n. 4, Out./Dez. 2003. disponível em http://www.anpad.org.br/rac/vol 07/dwn/rac-v7-n4-cam.pdf acesso em 06/12/2010.

OLIVEIRA-CASTRO, G. A. de; LIMA, G. B. C.; VEIGA, M. R. M. Implantação de um sistema de avaliação de desempenho: métodos e estratégias. Revista de Administração, São Paulo, v. 31, n. 3, p. 38-52, jul./set. 1996. Disponível em:http://repositorio.bce.unb.br/bitstream/10482/1299/1/ARTIGO ImplantacaoSiste maAvaliacaoDesempenho.pdf ou http://hdl.handle.net/10482/1299

OSSO, S. Novos paradigmas da gestão de recursos humanos. Publicado em 10/10/2008.Disponível em http://www.gestaodecarreira.com.br/coaching/falarh/ novos-paradigmas-da-gestao-de-recursos-humanos.html acesso em 15/05/2010.

RUAS, R. Gestão por Competências: uma contribuição à perspectiva estratégica da Gestão de Pessoas. EA/UFRGS Selecionado para apresentação no Congress Internacional Gestão de RH - Nov/2003. Grenoble - França.

UBEDA, C.L.; SANTOS, C.A. A gestão de competências integrada à definição estratégica e à avaliação de desempenho humano: um estudo teórico. XXVIII ENCONTRO NACIONAL DE ENGENHARIA DE PRODUÇÃO. Rio de Janeiro, RJ, Brasil, 13 a 16 de outubro de 2008.

UHLIG, V. A gestão de desempenho por competências no Banco do Brasil. UFGRS, 2007. Disponível em www.lume.ufgrs.br/bitsream/handle/10183/14264/000649511.

ZANELLA, L. C. H. Metodologia da pesquisa. Apostila elaborada para o curso de administração na modalidade a distância. Brasília: UnB, 2009. 


\section{APÊNDICE A - QUESTIONÁRIO}

Prezado(a) participante,

a Gestão de Desempenho baseada nas Competências adotada pela organização a que está vinculado(a) apresenta como principal objetivo oferecer uma estruturação básica capaz de orientar as decisões gerenciais no tocante à administração de pessoas. Esta pesquisa pretende verificar até que ponto a percepção dos funcionários acerca desse modelo influencia no seu comprometimento com o trabalho. Sua participação é muito importante, assim agradeço desde já a sua colaboração. Por favor, responda a todas as questões conforme solicitado.

\section{PARTE}

DADOS PESSOAIS

\begin{tabular}{|l|l|l|}
\hline Sexo & masculino & feminino \\
\cline { 2 - 3 } & & \\
\hline
\end{tabular}

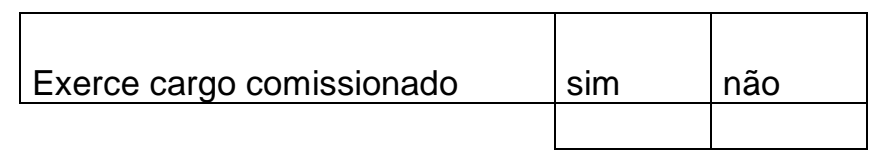

\begin{tabular}{|l|l|}
\hline Tempo no banco & anos completos \\
\hline
\end{tabular}

\begin{tabular}{|l|l|l|l|l|l|}
\hline $\begin{array}{l}\text { Escolaridade (se incompleto } \\
\text { favor indicar com inc. no campo } \\
\text { correspondente) }\end{array}$ & $\begin{array}{l}\text { ensino } \\
\text { médio }\end{array}$ & superior & $\begin{array}{l}\text { especiali- } \\
\text { zação }\end{array}$ & mestrado & doutorado \\
\hline
\end{tabular}

\begin{tabular}{|l|l|}
\hline $\begin{array}{l}\text { Favor indicar sua idade (em } \\
\text { anos completos) }\end{array}$ & anos completos \\
\hline
\end{tabular}


II PARTE

Assinale o quadro que represente o grau de sua concordância com cada uma das seguintes frases a respeito da Gestão de Desempenho baseada nas Competências (GDPC) adotada pela organização.

\begin{tabular}{|r|l|l|l|l|l|l|}
\hline & Item & $\begin{array}{l}\text { Discordo } \\
\text { plenamente }\end{array}$ & $\begin{array}{l}\text { Discordo } \\
\text { pouco }\end{array}$ & Em dúvida & $\begin{array}{l}\text { Concordo } \\
\text { pouco }\end{array}$ & $\begin{array}{l}\text { Concordo } \\
\text { plenamente }\end{array}$ \\
\hline 1 & $\begin{array}{l}\text { Auxilia o funcionário no seu } \\
\text { desenvolvimento profissional e } \\
\text { planejamento da carreira. }\end{array}$ & & & & \\
\hline 2 & $\begin{array}{l}\text { Possibilita que seja percebido o } \\
\text { entusiasmo, colaboração e dedicação com } \\
\text { que o funcionário desempenha suas } \\
\text { atividades. }\end{array}$ & & & & & \\
\hline 3 & $\begin{array}{l}\text { Auxilia para aumentar o comprometimento } \\
\text { do funcionário com a organização. }\end{array}$ & & & & & \\
\hline 4 & $\begin{array}{l}\text { Avalia adequadamente as competências e } \\
\text { experiências dos funcionários. }\end{array}$ & & & & & \\
\hline 5 & $\begin{array}{l}\text { Contém informaçães suficientes para } \\
\text { auxiliar no gerenciamento de equipes. }\end{array}$ & & & & & \\
\hline & $\begin{array}{l}\text { Auxilia na identificação dos funcionários } \\
\text { com competências e experiências } \\
\text { necessárias para atender às necessidades } \\
\text { da organização. }\end{array}$ & & & & \\
\hline 7 & $\begin{array}{l}\text { Valoriza a qualificação dos empregados } \\
\text { facilitando nas situações de } \\
\text { reconhecimento do mérito. }\end{array}$ & & & & \\
\hline 8 & $\begin{array}{l}\text { Consegue refletir exatamente os pontos } \\
\text { positivos e negativos do funcionário. }\end{array}$ & & & & & \\
\hline 9 & $\begin{array}{l}\text { É possível confiar nesse sistema de } \\
\text { avaliação de desempenho. }\end{array}$ & & & & & \\
\hline 10 & & & & & \\
\hline & & & & & \\
\hline & & & & & \\
\hline
\end{tabular}


III PARTE

As frases seguintes expressam os possíveis sentimentos com relação à organização. Assinale com um $X$ o quadro que represente o grau de sua concordância com cada uma delas.

\begin{tabular}{|r|l|l|l|l|l|l|}
\hline & Item & $\begin{array}{l}\text { Discordo } \\
\text { plenamente }\end{array}$ & $\begin{array}{l}\text { Discordo } \\
\text { pouco }\end{array}$ & Em dúvida & $\begin{array}{l}\text { Concordo } \\
\text { pouco }\end{array}$ & Item \\
\hline 1 & $\begin{array}{l}\text { Eu seria muito feliz em dedicar o resto de } \\
\text { minha carreira nesta organização. }\end{array}$ & & & & \\
\hline 2 & $\begin{array}{l}\text { Eu realmente sinto os problemas da } \\
\text { organização como se fossem meus. }\end{array}$ & & & & & \\
\hline 3 & $\begin{array}{l}\text { Eu não me sinto emocionalmente vinculado a } \\
\text { esta organização }\end{array}$ & & & & & \\
\hline 4 & $\begin{array}{l}\text { Esta organização tem um imenso significado } \\
\text { pessoal para mim. }\end{array}$ & & & & & \\
\hline 5 & $\begin{array}{l}\text { Se eu decidisse deixar esta organização } \\
\text { agora, minha vida ficaria bastante } \\
\text { desestruturada. }\end{array}$ & & & & & \\
\hline 6 & $\begin{array}{l}\text { Eu acho que teria poucas alternativas se } \\
\text { deixasse esta organização. }\end{array}$ & & & & & \\
\hline $\begin{array}{l}\text { Se já não tivesse dado tanto de mim nesta } \\
\text { organização pensaria em trabalhar noutro } \\
\text { lugar. }\end{array}$ & & & & & \\
\hline 8 & $\begin{array}{l}\text { Eu não sinto nenhuma obrigação de } \\
\text { permanecer nesta organização. }\end{array}$ & & & & & \\
\hline 9 & Esta organização merece minha lealdade. & & & & & \\
\hline 10 & Eu devo muito a esta organização. & & & & \\
\hline
\end{tabular}

IV PARTE

QUESTÃO ABERTA

Utilize este espaço para fazer alguma

observação sobre a GDPC.

\section{Grata pela colaboração!}

